\title{
Asian Pacific Digestive Week 2019 at Kolkata
}

J Digest Endosc 2020;10:245-245

Asian Pacific Digestive Week (APDW) was held in Kolkata between December 11 and 15, 2019, at Biswa Bangla Convention Center. It was a successful academic meet attended by 5,300 doctors from India and abroad. This year, APDW was merged with the annual meeting of the Society of Gastrointestinal Endoscopy of India (SGEI) along with ISG (Indian Society of Gastroenterology) and INASL (Indian National Association for the Study of the Liver).

Five hundred faculty members including more than 200 from overseas were involved in scientific deliberations.
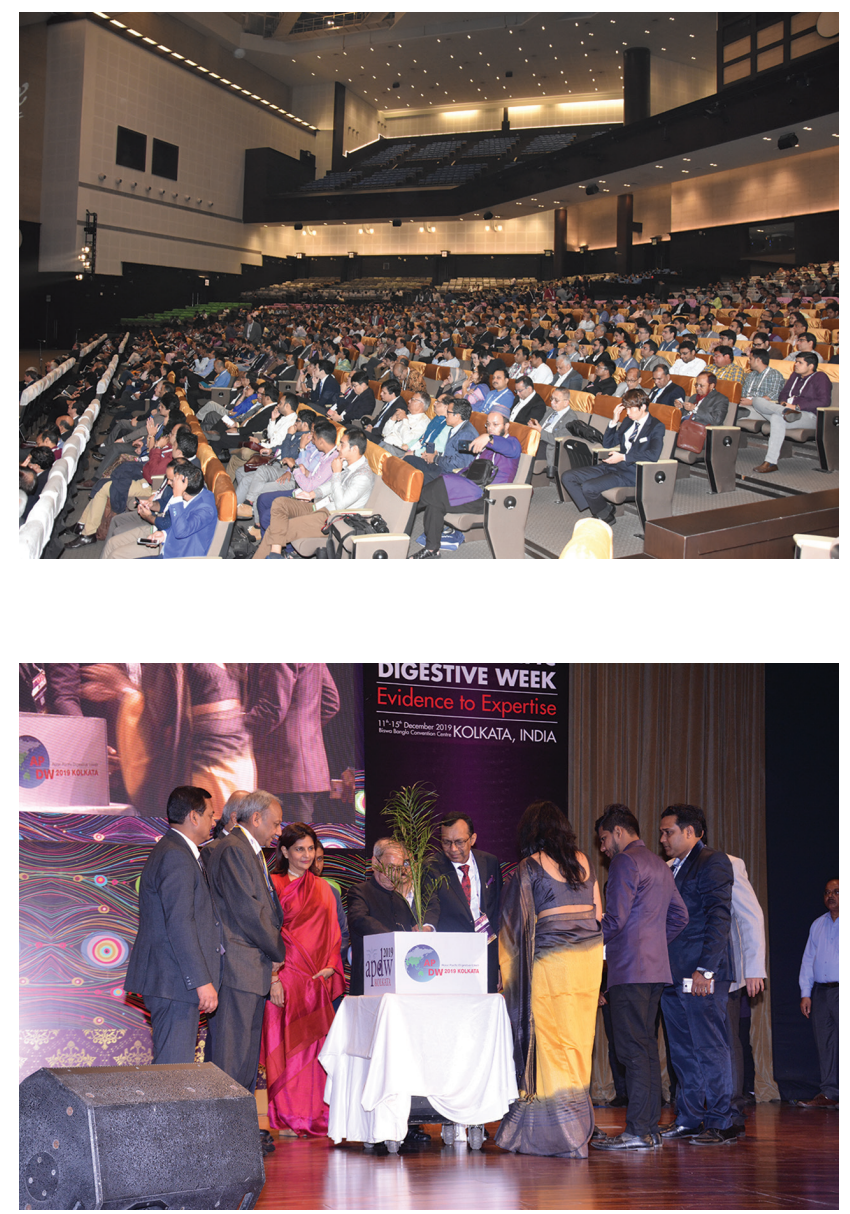

A record number $(1,621)$ of scientific abstracts were submitted. These included 1,061 oral presentations. Highlights included hands-on endoscopy sessions (16 slots, 763 participants), noiseless abstract meetings, Asian Pacific Endoscopy Cup, and live demonstration of 34 advanced endoscopic procedures from Apollo Gleneagles Hospital.

SGEI supported 20 young physicians to attend the meeting and present their work.

None declared.
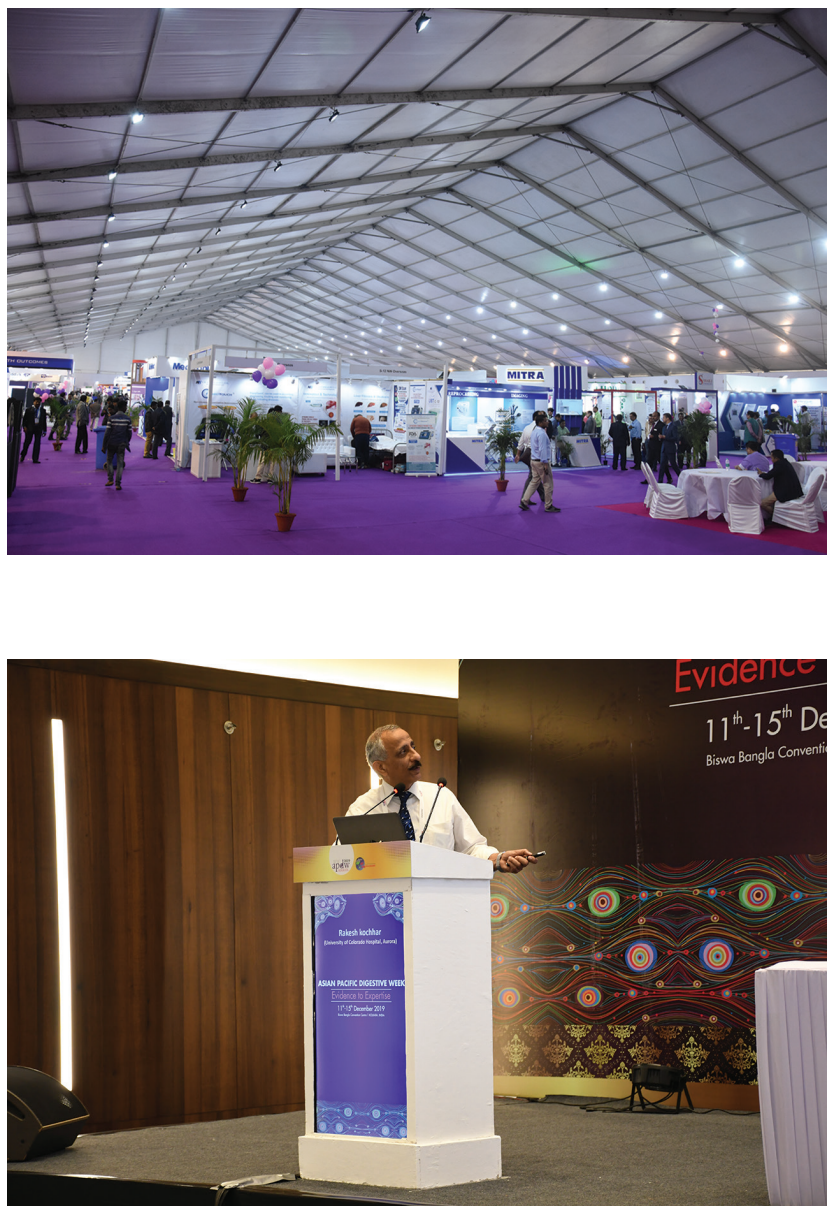

Copyright $\odot 2020$ Society of Gastrointestinal Endoscopy of India 